\title{
A (des)valorização intelectual do estudante da EJA
}

Géssica Gaspar ${ }^{1}$

\section{RESUMO}

Este estudo apresenta uma discussão sobre as relações de autoestima do estudante da Educação de Jovens e Adultos, numa perspectiva de desvalorização intelectual, sobre um contexto sócio-histórico desigual. Resultado da pesquisa em campo numa escola da rede municipal de Curitiba no ano de 2018 movida pela disciplina de Estágio em Docência no Ensino Fundamental do curso de Pedagogia da Universidade Federal do Paraná. Desta forma, visa perceber o perfil do estudante da EJA enquanto um sujeito excluído socialmente do espaço escolar, e que decide, numa prática de liberação retornar à escola. Por conseguinte, convidar a/o leitora/o à reflexão sobre a desvalorização intelectual discente nas suas relações com a leitura e escrita. E neste sentido, compreender como a valorização destes estudantes dialoga com a ética docente e sua prática escolar.

Palavras-chave: Educação de Jovens e Adultos; Desvalorização intelectual; Desigualdade social.

\begin{abstract}
This paper presents a discussion about the Youth and Adult Education student self-esteem relations, in an intellectual devaluation perspective, over an unequal social-historic context. Result of the field research in a public school in the city of Curitiba in the year 2018, caused by Teaching Internship in Elementary School class of Pedagogy course of the Federal University of Paraná (UFPR). Thus, it aims to notice the Youth and Adult Education student profile, while a socially excluded person from the school, and then he decides, in a liberation practice, to return to school. Therefore, it invites the reader to reflect about the student's intellectual devaluation in their write and reading relations, in addition, with the docent ethic and school practice.
\end{abstract}

\footnotetext{
${ }^{1}$ Graduanda em Pedagogia pela Universidade Federal do Paraná. Email: gaspar.ufpr.gu@gmail.com.
} 
Key-words: Youth and Adult Education; Intellectual devaluation; Social inequally.

$$
\begin{array}{r}
\text { Com efeito, para que sejam favorecidos os mais favorecidos } \\
\text { e desfavorecidos os mais desfavorecidos, é necessário e } \\
\text { suficiente que a escola ignore, no âmbito dos conteúdos do } \\
\text { ensino que transmite, dos métodos e técnicas de } \\
\text { transmissão e dos critérios de avaliação, as desigualdades } \\
\text { culturais entre as crianças das diferentes classes sociais }
\end{array}
$$

(BOURDIEU, 1998, p. 53).

\begin{abstract}
At través das produções e experiências possibilitadas pela disciplina de Estágio em Docência no Ensino Fundamental do curso de Pedagogia da Universidade Federal do Paraná no ano de 2018, algumas reflexões sobre a realidade que cerca a Educação de Jovens e Adultos (EJA) tornaram-se inquietantes. A turma de EJA de uma escola da rede pública municipal de Curitiba, que se localiza no bairro periférico, teve suas as noites acompanhadas durante todo o segundo semestre letivo do referido ano. Ela era composta majoritariamente por senhoras e senhores já aposentados, donas de casa, avós e avôs experientes, cheios de histórias e saberes para compartilhar. Eles moravam na região na escola, se encontravam e conviviam em outros momentos, encontraram na Educação de Jovens e Adultos uma forma de resgatar o contato com o ensino. O objetivo do estágio com a turma e dele na graduação de Pedagogia, foram apresentados às/aos estudantes que demonstraram receptividade e acolhimento de imediato, inicialmente o acompanhamento da turma foi descrito de cunho de pesquisa e prática docente. Porém, ao longo da experiência do ano letivo a proximidade com as/os estudantes despertou motivação em compreender as histórias trazidas pelas/os estudantes, ouvir seus anseios, interagir com suas dificuldades, assim visando dialogar estes saberes com os autores que
\end{abstract}


apontam as especificidades da Educação de Jovens e Adultos e a alfabetização e letramento nesta etapa tão singular.

A pesquisa de abordagens etnográficas foi realizada como observação participante (GIL, 1987, p. 103-104), ao longo das práticas escolares houve envolvimento ativo e natural, pois a espontaneidade e as diversas situações pertencentes ao cotidiano escolar da sala da EJA emergiam na relação desta temática com frequência. Nos primeiros dias de observação foi elucidado sobre o registro, que num relatório contendo algumas falas das/os estudantes bem como algumas situações seriam elencadas, estes cientes e interessados nos registros frequentemente questionavam se havia tomado nota de determinada fala proferida em algum momento da aula. Os relatos das/os estudantes trazidos neste estudo ocorreram sob a perspectiva da entrevista informal (GIL, 1987, p. 111-p.112), bem como aqui possuem nomes fictícios, a fim de preservação da identidade, porém os registros foram realizados de forma fiel, buscando contextualizar sua origem.

A Educação de Jovens e Adultos é regulamentada pela Lei de Diretrizes e Bases 9.394/96 na seção V a fim de direcioná-la àqueles que não acessaram ou não permaneceram na educação básica. De modo que seja gratuita e que contemple as características das/os estudantes, os seus interesses, e suas condições de vida e trabalho, pois desta vez, almeja-se favorecer a sua plena permanência. A LDB traz a Educação enquanto direito:

Art. $4^{\circ}$ O dever do Estado com educação escolar pública será efetivado mediante a garantia de:

[...] IV - acesso público e gratuito aos ensinos fundamental e médio para todos os que não os concluíram na idade própria;

[...] VII - oferta de educação escolar regular para jovens e adultos, com características e modalidades adequadas às suas necessidades e disponibilidades, garantindo-se aos que forem trabalhadores as condições de acesso e permanência na escola; 
[...] Art. 24. A educação básica, nos níveis fundamental e médio, será organizada de acordo com as seguintes regras comuns:

[...] $\S 2^{0}$ Os sistemas de ensino disporão sobre a oferta de educação de jovens e adultos e de ensino noturno regular, adequado às condições do educando, conforme o inciso VI do art. $4^{\circ}$. (BRASIL, 1996, grifo meu).

Quer dizer, a função equalizadora e reparadora da EJA como trazida no Parecer do Conselho Nacional de Educação/Câmara de Educação Básica (CNE/CEB) no 11/200o diz respeito à compreensão da singularidade desta modalidade, e dispor nela e para ela considerações que atendam suas especificidades a fim de promover, com efeito desta vez, a permanência. Isto é, uma vez que o direito à educação foi negado anteriormente à estes sujeitos, a concepção de função equalizadora da EJA almeja contemplar o quesito de desfavorecimento social e cultural dentro da escola, enquanto a reparadora possui um sentido histórico que:

[...] significa não só a entrada no circuito dos direitos civis pela restauração de um direito negado: o direito a uma escola de qualidade, mas também o reconhecimento daquela igualdade ontológica de todo e qualquer ser humano. Desta negação, evidente na história brasileira, resulta uma perda: o acesso a um bem real, social e simbolicamente importante (BRASIL, 200o, p. 7).

A realidade da EJA mostra-se muito característica, pois o gosto pela conversa é tomado pelas aulas, o ritmo calmo nas produções das propostas pedagógicas deve ser considerado nos planejamentos, bem como as abordagens docentes ao longo da metodologia das aulas devem concernir ao público discente. Quer dizer, esta realidade não é padronizada, intrínseca ou hegemônica em sua totalidade, no entanto, devido sua educação ser voltada para o público que não frequentou a escola em idade adequada, possui similaridades quais permitem traçar 
um perfil estudantil. Estudantes quais, foram excluídos da escola, ${ }^{2}$ e muitas das vezes tiveram seu processo de alfabetização negado (FERRARO; ROSS, 2017, p. 18), e agora, retornam para as mesas e cadeiras escolares com objetivos dos mais diversos.

Alguns estudantes almejam aprender a escrever seu nome, outros ler o nome dos ônibus que passam próximo a sua residência, ler o seu próprio documento, e até mesmo, há aqueles mais jovens que desejam concluir a educação básica, e com o diploma (re)qualificar-se para o mercado de trabalho. Ou mesmo, como a sra. Claudia da turma de EJA do estágio realizado qual inspirou e viabilizou este estudo, ela relatou querer "saber preencher uma ficha com seus dados, sem a moça da recepção precise me ajudar ou fazer por mim”. Incontáveis são as razões que os fazem retornar, e mais incontáveis são os desafios da educação inerentes à sua permanência.

Com base nas vivências observadas nas aulas da turma de EJA, é possível qualificar a extroversão dos estudantes da EJA ao trazer suas histórias de vida e relatos pessoais. No entanto, quando há ponderações da professora de caráter conteudista, quer dizer, nos momentos em que suas abordagens remetem a conhecimentos intrínsecos à temática da aula propriamente dita: muitos estudantes se retraem. Compreendendo assim, que o engajamento destes pela aula, num sentido de contribuições orais, ocorre de forma mais energizante quando a mesma apresenta um cunho mais informal, assemelhando-se a conversas corriqueiras entre seus pares.

Quer dizer, na disparidade da informalidade no tratamento e condução das aulas, imerge-se num comportamento omisso discente, onde aquelas estudantes tão falantes e ativas entre seus pares, e até mesmo com a professora nestas circunstâncias; ao se depararem com uma

${ }^{2}$ Alceu Ravanello Ferraro e Steven Dutt Ross (2017) em Diagnóstico da escolarização no Brasil na perspectiva da exclusão escolar, versam sobre a exclusão da e na escola enquanto discussão teórica, amostral, estatística num fator descritivo, uma vez que o excluso possui gênero, cor, classe social, e afins. 
abordagem docente sobre o conteúdo da disciplina, abstém-se da interação com a aula, mostrando uma atipicidade em seus comportamentos. Este notável cenário acerca da (in)disponibilidade discente em expor seus saberes em meio a aula, é a grande problemática deste estudo.

Buscando uma justificativa histórico-pedagógica sobre o contrato implícito da configuração em sala de aula, isto é, a relação docentediscente, onde os estudantes da EJA por natureza de suas experiências anteriores na escola, posicionavam-se passivamente frente à/ao mestre que detém os saberes e o controle da sala de aula. Por conseguinte, podemos realizar uma análise convidativa à reflexão quanto à valorização dos saberes discentes, enquanto veículos da promoção de uma educação libertadora e emancipadora (FREIRE, 1998), e então dialogar com a alfabetização e letramento nesta modalidade da educação básica. E por fim se apresentam as considerações finais do estudo, que provocam o exercício docente na EJA sob o prisma da ética e práticas que corroboram com os apontamentos trazidos ao longo do presente.

\section{RESQUÍCIOS DE UM ENSINO TRADICIONAL NA EJA}

\section{Liberação de uma pedagogia autoritária}

A pedagogia tradicional qual configura a/o docente no papel central e ativo nas práticas em sala de aula, é a maior referência empírica dos jovens e adultos que retornam às escolas através da EJA. Isto é, os jovens e adultos da EJA vivenciaram uma configuração escolar, atualmente, lida socialmente opressiva e pedagogicamente caracterizada como educação bancária (FREIRE, 1998). Neste sentido, deve-se tratar como real a perspectiva daqueles que possivelmente vivenciaram aulas unicamente expositivas, castigos físicos, autoritarismo docente e relação 
hierárquica e vertical em sala de aula e afins. A compreensão que aqueles estudantes da EJA carregam as marcas de uma escola excludente e opressora em suas histórias de vida, trata-se do ponto de partida para o questionamento central deste estudo, e os desafios esmiuçados por ele. A sra. Maria da turma da EJA, relatou: "eu tinha uma professora que fazia ronda no meio das mesas da gente, nunca vou esquecer quando ela rasgou a folha do caderno porque eu copiei errado, cheguei em casa a mãe brigou, me bateu porque o caderno estava rasgado!".

Diante disto, ao se conceber na história a tendência pedagógica tradicional e a relação desta na construção do sujeito social, considera-se amparado o dilema da (des)valorização intelectual destes estudantes. Quer dizer, num primeiro momento, a educação e suas práticas, a escola e suas configurações sociais são apresentadas de formas arbitrárias, ocasionando a negação educacional e exclusão social do sujeito. Num segundo momento, o sujeito decide retornar à escola, na EJA, e dele desta vez, é demandando um comportamento diferenciado, nesta ocasião, trajando-se como tendência pedagógica crítica, qual almeja ouvi-lo e valorizá-lo. Sendo as práticas de liberação ${ }^{3}$ de uma pedagogia autoritária, que possivelmente ocorrem no segundo momento do estudante na escola, elas exercem papel fundamental sobre a sua permanência. Os desafios incitados até este momento, direcionam-se, à priori, em emancipar este sujeito a fim de libertá-lo do estado oprimido que lhe fora condicionado naquele primeiro momento na educação tradicional.

A construção de uma pedagogia libertadora, com métodos e processos que visam acolher e valorizar as histórias de cada sujeito deve ser contínua no contexto da EJA, numa concepção de práticas de liberdade. Quer dizer, vamos considerar uma proposta pedagógica atual, uma roda de conversa, por exemplo, onde confiança e conforto na

3 Ana Lucia Ratto (2017) esmuíça o tocante foucaultiano Liberdade, entre práticas de liberação e práticas de liberdade sobre as relações de poder. 
exposição de ideias são primordiais; a concepção da relação discentedocente, para o estudante da EJA, se remete a hierárquica vertical, com base em sua referência na tendência pedagógica tradicional. Nesta perspectiva, os estímulos de cunho emancipador e desconstrução de elementos autocratas nas práticas de aula devem ser constantes. Pois, se faz primordial, não somente reconstruir a imagem da professora ou professor, a fim de que esta viabilize confiança e relações positivas, bem como alimentar as práticas de liberdade dos estudantes no contexto dentro e fora da escola, isto é, enquanto estudantes e enquanto cidadãos críticos. Como salienta Freire: "Precisamos estar convencidos de que o convencimento dos oprimidos de que devem lutar por sua libertação não é doação que lhes faça a liderança revolucionária, mas resultado de sua conscientização." (FREIRE, 1998, p. 30).

\section{Insegurança discente e a dicotomia: erro e acerto}

A insegurança discente da EJA elencada neste estudo causa a sua indisponibilidade partícipe crítica nas propostas pedagógicas. Isto é, trata-se da hesitação do estudante em contribuir oralmente nas aulas, em realizar tentativas, escritas ou demais respostas que possibilitem uma avaliação ${ }^{4}$ de aprendizagem. Quer dizer, o medo do erro é uma realidade estruturada por uma pedagogia tradicional que vincula os castigos físicos, a vergonha e a ridicularização à quem erra. Se tratando de um elemento real a ser desconstruído no processo de ensino-aprendizagem, a partir do medo de errar é revelado o comportamento de abstenção devido a sua autopunição como traz Luckesi:

4 Fernandes e Freitas (2007) abordam a avaliação formativa enquanto instrumento diagnóstico reflexivo do processo de ensino e aprendizagem, desfocando a mensuração da aprendizagem do estudante, mas consideranto todo o contexto dos elementos acerca daquele processo, inclusive das estratégias docentes, como sugere este estudo. 


\begin{abstract}
A partir do erro, na prática escolar, desenvolve-se e reforça-se no educando uma compreensão culposa da vida, pois, além de ser castigado por outros, muitas vezes ele sofre ainda a autopunição. Ao ser reiteradamente lembrado da culpa, o educando não apenas sofre os castigos impostos de fora, mas também aprende mecanismos de autopunição, por supostos erros que atribui a si mesmo (LUCKESI, 1999, p. 51).
\end{abstract}

Situação observada na turma da EJA que corrobora com a supracitada autopunição, é sobre a constante negação da sra. Maria Lurdes em suas tentativas de escrita, dizendo constantemente "eu não sei", "não consigo", "minha letra é feia" e etc. Tais premissas, e crenças delas por parte discente e docente inibem o progresso no processo de ensino e aprendizagem. Quer dizer, o papel docente, numa perspectiva ética, tratase do encorajamento intelectual do estudante, e a construção de um pensamento confiável que a tentativa, indiferentemente levada ao erro ou acerto, é a ferramenta mais aguçada que guia à aprendizagem numa perspectiva de pedagogia libertadora.

Assim como traz Arroyo (2006, p. 23) que este novo contato com a educação, com uma nova oportunidade de continuar sua escolarização; promovendo novas experiências e saberes, e não sua carência deles. Para ilustrar, pode-se trazer a superestimada dificuldade em matemática como exemplo, pois trata-se de uma cultura que enaltece as dificuldades para aprendê-la, não somente na EJA, mas num panorama discente que abrange todas as etapas e modalidades da Educação. Um hábito recorrente observado na turma da EJA: os estudantes ao descobrirem que a aula seria de matemática, estes lamentavam-se, inquietos e em estado de negação; inclusive, a professora revelou que alguns estudantes deixavam de ir à aula quando ela informava que haveria aula de matemática no dia seguinte. À vista disto, a suposta dificuldade matemática deve ser desmistificada, uma vez que sua aplicabilidade é diária e constante. Isto é, 
há etnomatemática ${ }^{5}$ no cotidiano dos estudantes. Consequentemente, deve-se construir um elo na metodologia usada entre: a realidade dos estudantes e as operações matemáticas, de forma que não somente valorize os saberes dos estudantes, mas que também traga significado àquele conhecimento novo. Duarte Junior (1982) traz que "quando a educação não leva o sujeito a criar significações fundadas em sua vida, ela se torna simples adestramento: um condicionamento a partir de meros sinais" (p. 56).

Assim sendo, no tocante ação partícipe ativa dos estudantes no processo de ensino e aprendizagem da EJA, numa perspectiva de valorização da autoestima sobre seus conhecimentos, pode-se notar a necessidade em se promover a autovalorização intelectual destes estudantes (FREIRE, 1967). Isto é, o que se almeja de fato, são encaminhamentos que visem a valorização numa perspectiva sócio construtivista entre o saber e o saber fazer. Quer dizer, uma ponte entre o conhecimento prévio do estudante e a sua articulação no processo de ensino aprendizagem, ou ainda como traz Esteban (2001, p.32) os "ainda não-saberes”, “ pois revela novos conhecimentos que se fazem não só necessários como também possíveis.”. Desta forma, que a relação dos estudantes com as abordagens escolares, seja tão espontânea quanto uma relação informal entre seus pares, pois, sabe-se que há preestabelecido um prejulgamento maniqueísta de certo ou errado, resquícios de uma perspectiva de pedagogia tradicional, e uma educação bancária (FREIRE, 1997). Neste sentido, a maior insegurança discente revelada aqui, trata-se do receio do fracasso, do erro e, por conseguinte, da negação de pertencimento àquela sala de aula.

A partir disto podemos reflexionar a hesitação do estudante da EJA nas aulas como medo do erro, do fracasso, de julgamento intelectual

${ }^{5}$ D’Ambrósio Ubiratan (2001) é um dos pioneiros a trazer a Etnomatemática, enquanto uma proposta que visa contemplar a matemática em compreensões próprias da realidade social, cultural e histórica de cada sujeito ou grupo em questão. 
que os condenem insuficientes, e que ainda, venha a contribuir com o sentimento de negação de pertencimento do estudante naquela sala de aula, naquela escola, com seus livros e cadernos. Isto é, a pura incerteza do estudante em (re)ocupar um espaço escolar é um contribuinte carente de autoestima e ações afirmativas de legitimidade em (re)apropriar-se criticamente da educação que lhe deve ser assegurada. Para tanto, a busca por desvencilhar valores tradicionais oriundos de uma escola que não acolheu estes estudantes anteriormente, para uma nova escola cujas abordagens mostram-se, possivelmente, mais dialéticas, livres e passíveis das colaborações discentes, torna-se um dos maiores desafios na Educação de Jovens e Adultos em geral.

\section{ESCRITA E LEITURA COMO PROPRIEDADES DE INTELECTO}

O destino da palavra é o da sociedade que fala (BAKHTIN, 1992 p. 148).

\section{A dignidade da escrita}

A escrita e a leitura tratam-se de elementos superestimados pela sociedade, sendo decisivos para a aceitação dos sujeitos em campos ${ }^{6}$ letrados. Quer dizer, saber escrever e ler são habitus que dialogam a inclusão ou exclusão social de um indivíduo, pontuando inclusive, em sua trajetória e vivências em detrimento outras possibilidades de acesso ao mundo social e cultural. Quer dizer, a escrita e leitura não se tratam somente de status social, numa perspectiva de capital social que viabiliza uma desenvoltura letrada em determinados campos. Tratam-se, inclusive, de atributos provedores de acesso potencial à cultura, a aquisição de

${ }^{6}$ Pierre Bourdieu e Passeron (1992) em A Reprodução: Elementos para uma Teoria do Sistema de Ensino, elencam a linguagem enquanto elemento determinante de status social, violência simbólica e propagador de desigualde social na escola. 
capital cultural, conhecimentos científicos, literários, artísticos, históricos, entre outros.

Ao se contextualizar tal concepção da leitura e escrita na realidade dos estudantes da EJA, podemos compreender quão significativo pode se tratar o ato da escrita realizada por eles. Quer dizer, nota-se que o ato de escrever carrega um significado erudito, bem como, no quê se escreve carrega o mesmo peso, ou até maior. Com base nas observações e práticas do estágio mencionado no início deste estudo, foi notada hesitação dos estudantes no ato da escrita autônoma, aquela escrita idealizada por eles, não copiada ou ditada por outrem, aquela escrita que exige reflexão e planejamento de quem a escreve. Quer dizer, esta hesitação, podendo ser lida como receio, insegurança ou qualquer outro termo que impeça o estudante da EJA em auto (des)valorizar seus saberes. Isto é, as relações do maniqueísmo: erro e acerto, enquanto um prejulgamento das falas e contribuições dos estudantes remete a uma ponderada indisposição à escrita. Numa atividade observada que os estudantes da turma da EJA deveriam escrever um breve texto relatando uma memória de sua infância, dona Regina relatou não ter nenhuma lembrança "boa para escrever", porém, em conversa, disse que mesmo com a infância difícil onde trabalhava na roça com seus irmãos, gostava de tomar banho no rio e brincar no milharal com eles, dona Regina disse que não era uma história bonita para escrever. Assim como o sr. Antônio, que revelou que aos 7 anos começou a beber cachaça e aos 10 a fumar cigarro palheiro, o mesmo relatou "isso é feio, não vou escrever isso, não". Retomando: aqui o conteúdo da escrita tem igual ou maior peso intelectual que o ato da escrita em si.

Há momentos nos processos de escrita, quando o escritor de fato reflete sobre as palavras, locuções e vocabulários a serem utilizados: perfeitamente aceitável e universal para quem escreve. Não obstante, não se trata da situação aqui revelada. Anseio em trazer que há a necessidade 
de se reconhecer e legitimar os saberes dos estudantes como estimados à escrita. Enquanto houver estudantes da EJA subjulgando suas próprias falas, relatos, criações e saberes como insuficientes para escrevê-los, a desconstrução da auto desvalorização intelectual desses estudantes se tratará da ignição necessária para o processo de escrita autônoma.

Ao esmiuçar a problemática da autodesvalorização intelectual do estudante da EJA, podemos elencar algumas considerações para que se possa converter a concepção negativa de um saber, para algo digno da escrita. Isto é, em atividades que propõem criação de frases, práticas com memórias que envolvem a escrita delas, ou mesmo qualquer conjunto de ideias baseadas na carga de saberes destes estudantes, podem ser concebidas por eles como locuções baseadas em seu achismo, seu senso comum, num repertório de saberes distinto aos saberes científicos. Como afirma Esteban (2001, p. 17) "saber que não sabem é uma dura aprendizagem de uma falsa verdade”. Neste sentido, é possível que a concepção que uma ideia seja (in)digna de escrita, está atrelada a formulação de frases eruditas e vocabulário rebuscado. Como se o mérito da escrita, fosse atribuído somente às palavras mais bonitas e difíceis, às frases e orações mais elaboradas. Entretanto, qualquer sujeito íntimo da escrita compreende que qualquer fala, relato ou ideia oralmente reproduzida, pode ser efetivamente representada pela escrita, contando com instrumentos como aspas, travessão, pontuações e afins. Diante disto, podemos afirmar ao estudante da EJA, que qualquer pensamento por ele proferido é prontamente digno da escrita. Por exemplo, o estudante Francisco da turma que em determinada atividade onde ele deveria escrever uma pequena legenda sobre o significado de alguns elementos de uma foto, o mesmo verbalizou um texto curto, porém suficiente, de vocabulário simples, mas que contemplava a atividade efetivamente; Francisco relatou que não ficaria "bonito" como o que a professora havia escrito. Neste sentido, é aceitável que trata-se de um 
desafio no processo do próprio letramento ${ }^{7}$ do estudante, para tanto, a valorização intelectual dele e de seus saberes, faz-se primordial nas (re)lutas em considerá-los dignos de escrita. Como traz Freire:

\begin{abstract}
Nessa perspectiva, portanto, os alfabetizandos assumem desde o começo da ação o papel de sujeitos criadores. Aprender a ler e escrever já não é mais memorizar sílabas, palavras ou frases, mas sim refletir criticamente sobre o próprio processo de ler e escrever e sobre o profundo significado da linguagem (FREIRE, 2002, p. 49).
\end{abstract}

\title{
Finalidade da escrita
}

Ao introduzir as concepções de leitura e escrita num aspecto filosófico lingüístico, podemos compreendê-las como expressões de comunicação social entre os indivíduos num meio social determinado, como afirma Bakhtin (1992). Neste sentido, tudo trata-se de comunicação. A razão de se codificar falas, pensamentos e ideias em letras, é a comunicação entre os grupos sociais, entre os próprios indivídios. Isto é, a real finalidade da escrita é a comunicação. Compreender-se enquanto sujeito expressivo, e a partir da escrita exteriorizar seus relatos, reflexões e sentimentos para outrem, é a mais pura e legítima finalidade da escrita. Isto posto, o normativismo ${ }^{8}$ linguístico - qual ainda predomina no contexto escolar - trata-se de uma dura barreira social e linguística para a escrita autônoma do estudante da EJA. Uma vez que a cobrança social linguística é normativista, a desconstrução desse preceito numa (re)educação de jovens e adultos é essencial, a fim de se legitimizar a sua

${ }^{7}$ Para Magda Soares (2004), o letramento trata-se de um conceito mais amplo da leitura e escrita, com contexto; propósitos; escrita e leitura enquanto formas de expressão; leituras de mundo; valor social, entre outros.

${ }^{8}$ Carlos Alberto Faraco (2007) em a Linguagem, escola e modernidade traz uma relevante crítica ao normativismo linguístico enquanto norma que padroniza a língua, tolhindo as variedades, informalidades da língua e afins (modernidade), onde predomina-se a "norma culta" exclundente. 
história, realidade social e autonomia no ato da escrita. Desta forma, como Faraco (2007, p. 58) retrata o desafio em se trazer a modernidade para dentro da escola:

\begin{abstract}
Assim, num tempo em que alguns estão desencando no debate ideológico os projetos da modernidade, quero concluir pela defesa da necessidade ainda urgente de perseguí-los no contexto da escola, o que significa fundamentalmente democratizá-la. E fazê-lo não somente pela universialização do acesso, mas também de permanência. Democratizá-la também pela construção de práticas pedagógicas eficientes e eficazes que garantam a progressiva autonomia do aprendiz como parte do processo de sua imersão no espaço da cidadania, o que, no contexto específico da educação linguística, passa pela elaboração de práticas que rompam com a visão estática do normativismo e todas as suas consequências, trabalhando com a linguagem, oral ou escrita, não num bloco pétreo a ser engolido, mas como uma complexo conjunto de atividades socioverbais conectadas com o conjunto das práticas sociais.
\end{abstract}

Nesta perspectiva normativista inserida dentro da escola, (FARACO, 2007, p. 57) pontua-se o impasse entre a correção de erros ortográficos dos estudantes da EJA, e o incentivo a escrita autônoma: qual respeita as variedades sociolinguísticas, bem como emancipa o estudante jovem/adulto ao ato da escrita. Quer dizer, numa concepção pedagógica qual inere o processo de ensino-aprendizagem inculcada na práxis, podemos reflexionar o papel docente frente ao dilema da imposição normativista à escrita do estudante da EJA com imprescindível cautela. Porquanto, o papel docente jamais deve ter caráter de imposição absoluta do saber; entretanto a orientação que beneficie as aprendizagens e o aperfeiçoamento delas se trata da prática que melhor se encarrega frente à este dilema. Sustentando isto posto, Esteban (2001, p. 88) traz:

O/a professor/a como profissional reflexivo vai compreendendo que participa da aprendizagem dos alunos e alunas, mas não a determina, e procura adquirir ferramentas conceituais e práticas para atuar de modo favorável à aprendizagem e ao desenvolvimento. 
Por conseguinte, podemos dialogar a problemática da valorização intelectual do estudante da EJA enquanto veículo essencial para sua emancipação enquanto propósito docente. Quer dizer, compreendendo a prática docente como a práxis participativa nos processos de ensino e aprendizagem, prezar pelos saberes discentes da educação de jovens e adultos, trata-se de um ato imprescindível docente. Pois, sua valorização enaltece a autonomia da aprendizagem, a autoestima do saber, e sobretudo, a emancipação do oprimido. Freire (1997, p. 66-67) versa sobre o respeito e olhar estimado ao discente enquanto quesito ético:

O respeito à autonomia e à dignidade de cada um é um imperativo ético e não um favor que podemos ou não conceder uns aos outros. [...] Saber que devo respeito à autonomia e à identidade do educando exige de mim uma prática em tudo coerente com este saber.

\section{Considerações finais}

Com base nos apontamentos discorridos ao longo deste estudo crítico, à priori, elenca-se enquanto premissa docente o olhar cuidadoso e atenção voltados a conhecer o contexto escolar, tanto com relação aos saberes discentes, quanto a realidade qual estes estão e estiveram imersos, seja no âmbito social e histórico. Aqui pontua-se a desigualdade social, enquanto problemática sistêmica escolar que corrobora com a própria desvalorização intelectual do estudante da EJA. Isto é, estar consciente das histórias, sentimentos, anseios e trajetórias que o estudante da EJA percorreu, não se trata unicamente de uma prática docente pedagógica enquanto contextualizadora do processo de ensino aprendizagem, porém, inclusive de uma prática humana com seus pares, ou seja, de se conhecer com quem se convive. 
Neste sentido, podemos ver a escola como o ambiente próprio para promoção do desenvolvimento e práticas que viabilizam o processo de ensino e aprendizagem. Desta forma, compreendendo este caráter instigador educacional contextualizado num panorama social desigual, o papel da escola na Educação de Jovens e Adultos visa não promover a reprodução das desigualdades sociais. Esta constante reprodução de desigualdades da sociedade na escola, de forma dialética, é um grande desafio para aquelas escolas que atendem os mais desfavorecidos (BOURDIEU, 1992).

A autodesvalorização intelectual dos estudantes tão apontada neste estudo, quando não abordada pelo docente de forma que vise sua libertação, corrompe qualitativamente a autoestima deles em três esferas. Primeiro, ao corroborar com a premissa inicial condutora à negação do direito histórico à educação; assim inviabilizando a atuação da EJA na função reparadora (BRASIL, 200o). Segundo, ao não reconhecer-se intelectualmente pertencente àquele espaço educacional, compreendendo suas dificuldades como "ainda não-saberes" (ESTEBAN, 2001, p. 32); há a desvalorização enquanto estudante. Terceiro, ao não conceber-se como sujeito de saberes inerentes à sua realidade, de forma emancipada, há sua desvalorização enquanto cidadão. Pois, "no sentido de ausência de conhecimentos relevantes, é assumir uma identidade que se fundamenta na desvalorização de si como indivíduo e como sujeito social" (ESTEBAN, 2001, p. 18).

Por fim, considera-se como concepção docente norteadora para a problemática da (auto)desvalorização intelectual do estudante da EJA, o respeito e tratamento com dignidade àqueles estudantes. Respeito aos seus saberes carregados de história e vida, e dignidade à relação docentediscente a fim de que não se reproduza uma desigualdade social, qual o próprio estudante busca erradicar, em sua legitimidade ao regressar ao 
espaço escolar. Isto, não tratando-se de uma relação humana entre seus pares, mas inculca num fundamento ético docente (FREIRE, 1997).

\section{REFERÊNCIAS}

ARROYO, Gloria Macapagal. Educação de jovens e adultos: um campo de direitos e de responsabilidade pública. In SOARES, Leôncio et al. Diálogos na educação de jovens e adultos. 2. ed. Belo Horizonte: Autêntica, 2006.

BAKHTIN, Mikail. Marxismo e Filosofia da Linguagem. São Paulo: Hucitec, 1992.

BORDIEU, Pierre; PASSERÓN, Jean-Claude. A reprodução: Elementos para uma Teoria do Sistema de Ensino. Rio de Janeiro: Francisco Alves, 1992.

Escritos de Educação. Petrópolis: Vozes, 1998.

BRASIL. Lei de Diretrizes e Bases da Educação Nacional-LDB. Lei n. 9394, 1996.

BRASIL. Conselho Nacional de Educação (CNE). Câmara de Educação Básica (CEB). Parecer n.ํㅜ 11/200o, de 07 de junho de 2000. Diretrizes Curriculares para Educação de Jovens e Adultos. Brasília, 2000.

D'AMBRÓSIO, Ubiratan. Sociedade, cultura, matemática e seu ensino. Revista Educação e Pesquisa, São Paulo, v. 31, 2005.

. Etnomatemática - elo entre as tradições e a modernidade Belo Horizonte: Autêntica, 2001.

DUARTE JUNIOR, João Francisco. Fundamentos Estéticos da Educação. São Paulo: Cortez, 1981.

ESTEBAN, Maria Teresa. O que sabe quem erra? Reflexões sobre avaliação e fracasso escolar. Rio de Janeiro: DP\&A, 2001.

FARACO, Carlos Alberto. Linguagem, escola e modernidade. In: GHIRALDELLI JR., Paulo. Infância, escola e modernidade. São Paulo: Cortez; Curitiba: Editora da UFPR, 2007. 
FERNANDES e FREITAS. Indagações sobre currículo: currículo e avaliação. Brasília: MEC/SEB, 2008, p.17-39.

FERRARO, Alceu Ravanello. ROSS, Steven Dutt. Diagnóstico da escolarização no Brasil na perspectiva da exclusão escolar. Revista Brasileira de Educação v. 22 n. 71, 2017.

FREIRE, Paulo. Educação como prática da liberdade. Rio de Janeiro: Paz e Terra, 1967.

Conscientização: teoria e prática da libertação: uma introdução ao pensamento de Paulo Freire. São Paulo: Cortez \& Moraes, 1979.

- Pedagogia da autonomia: saberes necessários à pratica educativa. 2. Ed: Rio de Janeiro: Paz e Terra. 1997.

Pedagogia do Oprimido. $25^{\underline{a}}$ ed. (1 $1^{\underline{a}}$ edición: 1970). Rio de Janeiro: Paz e Terra. 1998.

. Pedagogia da Indignação: cartas pedagógicas e outros escritos. São Paulo: Unesp, 2000.

. Ação cultural para a liberdade e outros escritos. 10. ed. São Paulo: Paz e Terra, 2002.

GIL, Antonio Carlos. Métodos e técnicas de pesquisa social. São Paulo: Atlas, 1987.

LUCKESI, Cipriano Carlos. Avaliação da aprendizagem escolar: estudos e proposições / Cipriano Carlos Luckesi. 9. ed .São Paulo: Cortez. 1999 .

RATTO, Ana Lúcia S. Apontamentos sobre as relações de poder em Foucault. Curitiba-PR:Universidade Federal do Paraná, Setor de Educação, mimeo., agosto de 2017.

SOARES, Magda. Letramento e Alfabetização: as muitas facetas. Revista Brasileira de Educação, n. 25, 2004. 